\title{
Mindfulness Meditation for the Treatment of Chronic Low Back Pain: A Preliminary Quasi- randomized Controlled Pilot Study
}

Cesare Lino ( $\nabla$ cesare.lino@gmail.com )

Marconi University

\section{Stefan Neuwersch-Sommeregger}

Klinikum Klagenfurt

Rudolf Likar

Klinikum Klagenfurt

Paola De Bartolo

Fondazione Santa Lucia

\section{Research Article}

Keywords: Chronic pain, mindfulness, MBPT, MBSR, meditation, multimodal pain management, low back pain

Posted Date: December 8th, 2021

DOI: https://doi.org/10.21203/rs.3.rs-1123107/v1

License: (9) This work is licensed under a Creative Commons Attribution 4.0 International License. Read Full License 


\section{Abstract}

Objective: To investigate the effectiveness of Mindfulness-Based Pain Therapy (MBPT) a treatment combining mindfulness meditation and several interventions taken from cognitive therapy within the frame of the multimodal pain therapy program, in patients suffering from chronic low back pain (CLBP).

Design: A quasi-randomized case-control study.

Subjects: The study included 20 subjects with chronic low back pain were recruited and quasi-randomly allocated to a standard multimodal pain therapy $(n=10)$ or to a multimodal pain therapy group with MBPT $(n=10)$. The intervention was identical for both groups except for the mindfulness meditation program.

Methods. Both groups participated in a 4-week training, 5 times/week. All subjects underwent the same measurement protocol before and after the intervention. The program was evaluated on the basis of measure of pain, quality of life, disability, pain catastrophizing and depression.

Results: The trial group displayed significant reduction in pain intensity, improvement in the quality of life, reduction in pain disability, in depression and pain catastrophizing.

Conclusion: The study indicated that mindfulness meditation can influence the treatments and lead to a significant improvement in the overall result of the multimodal pain therapy.

\section{Key Summary Points}

Chronic pain has a huge impact on the quality of life of the more than 1,5 billion people in the world with prevalence increasing with age and therefore is a global public health problem. Chronic pain is a challenge for health care systems and a leading cause of disability.

The multidisciplinary pain management, which involves a combination of physical exercise, patient education, relaxation techniques and medication, has been shown to be clinically effective although the treatment is not always satisfactory.

For this reason, alternative interventions, such as mindfulness meditation have been considered.

This research compared a mindfulness-based intervention (MBPT) with usual multimodal chronic pain management. We hypothesized that patients with chronic low back pain (CLBP) would show greater improvement in several measures compared to those who received the usual care.

The study indicated that mindfulness meditation can positively influence the treatment and lead to a significant improvement in the quality of life and can help to reduce pain intensity, pain disability, depression and pain catastrophizing of the patients 


\section{Introduction}

Chronic pain, defines as pain lasting longer than 12 weeks or past the normal time for tissue healing, is defined as an unpleasant sensory and emotional experience (IASP taxonomy 2012). It has a huge impact on the quality of life of the more than 1,5 billion people around the world who are living with this condition, with prevalence increasing with age. Chronic pain is a challenge for health care systems and a leading cause of disability in the world. In Europe it affects $20 \%$ of the population with total cost estimated to be in the region of $3-10 \%$ of gross domestic product. Chronic pain is therefore a global public health problem and has an unquestionable impact upon a patient's quality of life and is linked to lower quality of life.'

Although drugs, particularly opioids, are highly effective, their sole use, especially in the management of chronic non-malignant pain remains controversial and with undesirable side effects. They are not always a remedy and should not be used alone but form part of a multidimensional strategy that as well as analgesics includes non-pharmacological approaches, such as physical and psychological therapy and alternative therapies.

Comprehensive multidisciplinary pain management based on the biopsychosocial model of pain has been shown to be clinically effective and cost-efficient although the treatment is not always satisfactory.

Multimodal pain management is defined as "a comprehensive treatment of complex chronic pain syndromes, in which medical therapy is integrated with various other specialized therapeutic interventions provided by specialists from various areas of expertise, such as doctors, physiotherapists and psychologists based on the biopsychosocial model." The treatment involves a combination of physical exercise, patient education, relaxation techniques and medication.

The high pervasiveness and the persevering nature of chronic pain has led to increased interest in treatment plans which include alternative interventions, such as mindfulness meditation.

Mindfulness is defined as the awareness that emerges through paying attention on purpose, in the present moment, and nonjudgmentally to the unfolding of experience moment by moment.

Based on ancient Eastern meditation practices, mindfulness has in the last three decades achieved increasing interest as an integrative and alternative treatment for managing chronic pain.

Historically a Buddhist practice, mindfulness can be considered a universal human capacity proposed to cultivate clear thinking and openheartedness.

It is a mind state characterized by paying conscious attention to the moment-to-moment experience with acceptance and openness. Mindfulness meditation includes a variety of techniques that help focus attention in a non-judgmental way and avoid ruminative, persistent, or obsessive thinking. One of the goals of mindfulness is to allow thoughts to arise and to fade away, without meditators being emotionally "caught up" by their contents. 
Mindfulness was originally proposed as a clinical intervention utilized in the management of chronic pain and stress. Subsequently numerous interventions based on mindfulness have been developed encompassing from programs for patients with cancer to those with mental health problems.

Since then research on mindfulness-based interventions (MBI) has increased exponentially. MindfulnessBased Stress Reduction (MBSR), currently the most widely implemented meditation intervention regarding chronic pain, has been found to promote significant reductions in chronic pain, enhancement in emotion regulation as well as it can improve mental health.

This research compared MBPT with usual multimodal chronic pain management. We hypothesized that patients with CLBP would show greater improvement in several measures such as disability, pain intensity, pain catastrophizing and other outcomes compared to those who received the usual care.

\section{Materials And Methods}

\section{Subjects}

20 outpatients (women=15 men=5) with chronic low back pain (CLBP) were recruited by referrals from the hospital's internal pain, orthopedic and neurological clinics, general practitioners and specialist doctors. The MBPT group was significantly younger (43 \pm 7.15 years) than the control group $(54,5 \pm 8.54$ years, $p<0,026$ U-Test).

\section{Intervention}

Mindfulness-Based Pain Therapy (MBPT) is a program modeled by the first author after the curriculum developed by Kabat-Zinn et al. at the Stress Reduction Clinic of the University of Massachusetts Medical Center. As other mind-body approaches, MBPT focuses on increasing awareness and acceptance of present experience including physical distress and challenging thoughts and emotions.

Participants underwent individual intake interviews prior to admission in MBPT during which a short medical history was taken as well as informed consent procedures for participation in outcome research. Baseline measures were also obtained. Exclusion criteria included substance abuse, pregnancy, cognitive impairment, language barrier and severe mental disorders (such as psychotic symptoms). All participants were given usual medical care during the intervention.

Patients had no previous meditative experience. The intervention took place at the General Hospital of Klagenfurt am Wörthersee in Austria.

The study was approved by the medical ethics committee of the hospital of Klagenfurt am Wörthersee (Austria) (A12/19). All methods were performed in accordance with the relevant guidelines and regulations.

\section{Frequency and Setting}


MBPT-group was delivered by the first author, who is a MBSR trainer with extensive meditation teaching experience. An observing psychologist was also present at each session.

The control group was delivered by two licensed clinical psychologists of the general hospital of Klagenfurt with extensive experience in the multimodal pain therapy.

10 chronic pain patients (CLBP) were trained daily $(2 \mathrm{~h})$ in mindfulness meditation over a period of 4 weeks whilst the control group attended the standard multimodal pain management consisting of psychological group therapies, pain management and relaxation training, stress management training. Both groups received, from 8:00 a.m. to 12:00 a.m. medical therapies, coordination and endurance strength training as well as medical and psychological individual consultations.

Due to the relatively small number of participants available at a single time, it was not feasible to assign the participants randomly. For this reason, the allocation to treatment was based according to time of enrollment. The first 10 patients who enrolled were allocated to the control group, whereas the following 10 patients formed the MBPT-group.

\section{Program techniques}

The intervention was modeled closely by the first author after the MBSR program as taught at the University of Massachusetts Medical Center[i] and was delivered according to a manualized protocol. The MBPT program focuses specifically on chronic pain and involves a variety of mindfulness meditation techniques including: mindful breathing, body scan, mindful yoga, walking meditation, awareness of emotions and lovingkindness meditation (metta) practices as well as several techniques taken from cognitive therapy. Yoga was tailored to accommodate patients with chronic low back pain. MBPT differs from other mindfulness-based interventions (MBI) in that it entails more intensive daily meditative practice (at least 1 hour/day) 5 days per week. Moreover, participants were instructed to practice informal meditation, like being mindful in everyday activities (e.g. eating, walking, etc.). Daily class was divided between meditation practice, group discussions (in dyads or group). Written materials and recordings of guided meditations were provided, although participants were not explicitly instructed to practice at home. The didactic content included education about chronic pain, stress, sleep hygiene, functional and maladaptive pain-coping strategies, dysfunctional thoughts.

\section{Adherence}

One patient dropped out of the experimental group and one from the control group. Both dropped out due to unexpected family obligations. Program completion rate was very high $(90 \%)$ a rate consistent with other studies.[ii] Compliance to MBPT class attendance was very high. Of a total of 19 classes only 3 patients missed one class.

\section{1- and 3-month Follow-up}


Of the 9 participants in the experimental group who completed the MBPT program 7 were available for 1month and 3-month follow-up. In the control group 8 were available for 1-month follow-up and 7 for the 3month follow up.

\section{Data analysis}

Descriptive statistics were used for the variables between MBPT group and control group. Appropriate parametric or non-parametric tests were done. Variables were compared by U-test (Wilcoxon rank-sum test) resp. 2-sample t test (Welch test) in case of normally distributed data. Normality was investigated by Kolmogoroff-Smirnov test.

The progression of the differences of the medians over the measurement time points was tested with the signed-rank test. Spearman rank correlation coefficient was calculated to examine association between scores.

Significance was defined as a $p$ value less than 0.05 . $p$ values are reported to a maximum of three decimal places.

For all calculations the statistical package $\mathbf{R}$ version 4 resp. Hewlett-Packard RPL version 2.08 were used.

\section{Measures}

\section{Numerical Pain Rating Scale}

The Numerical Pain Rating Scale (NRS) is commonly used in clinical population in order to measure the intensity of pain. Patients choose before and after each session the number that best reflects the intensity of the pain, with 0 representing "no pain" and 10 indicating "worst pain imaginable". Several studies provide evidence for its reliability and validity.[iii], [iv]

\section{EuroQol 5-D}

The EuroQol-5D (EQ-5D) questionnaire is an instrument which assesses health status. The EQ-5D comprises two components: Health state description and evaluation: The EQ-5D-description is a selfreported explanation of health problems according to a five-dimensional classification (mobility, self-care, usual activities, pain/discomfort and anxiety/depression).[v] In the EQ-5D-evaluation, the respondents report their health status using a visual analogue scale (VAS), comparable to a thermometer. Chronic pain is associated with overall decreased quality of life. The scale is graduated from 0 (the worst imaginable health state) to 100 (the best imaginable state). EQ-5D showed a good responsiveness to change after different interventions for CLBP patients.[vi]

\section{Pain perception Scale PPS}

The Pain Perception Scale (PPS)[vii] allows a differentiated assessment of perceived pain. It permits measurement of the emotional characterization and the sensory characterization of pain, uncoupling the 
physical sensation from the emotional and cognitive experience of pain.[viii] The questionnaire contains 24 items assigned in 5 subscales.

\section{Pain disability index}

The Pain disability index (PDI) [ix] is a self-report questionnaire which investigate how much pain interferes in different areas of patient's life activity: such as family/home, recreation, social, occupation, sexual, self-care, life-support and average. The respondent uses a scale ranging from 0 (no disability) to 10 (maximum disability). The German PDI confirmed a good reliability and validity.[x]

\section{Beck Depression Inventory II}

Beck Depression Inventory II is a widely used 21-item self-report inventory for measuring the severity of depression.[xi] Numerous studies provide evidence for its reliability and validity.[xii] The German BDI-II shows good reliability and validity in clinical population.[xiii]

\section{Pain Catastrophizing Scale}

Pain Catastrophizing Scale PCS is a 13-item questionnaire that assesses catastrophizing, viewed as a multidimensional construct comprising rumination ("I can't stop thinking about how much it hurts"), magnification ("I worry that something serious may happen") and helplessness ("There is nothing I can do to reduce the intensity of the pain").[xiv] The score ranges from 0 to 52 . The German PCS represent a valuable tool in the assessment of German-speaking clinical population.[xv]

\section{Results}

At baseline, treatment groups were similar in pain characteristics.

\section{Numerical Pain rating Scale}

The differences in the NRS score medians (control group minus intervention group) were measured both before and after the therapy sessions (19 measurement points each).

These differences are highly significantly positive in both cases $(p<0.01$; signed rank test). The MBPT group demonstrates a significant decrease in pain intensity from baseline comparing with control group. Results indicate that pain intensity reduction was maintained over 1-month to 3-month follow-up periods.

The difference in the score medians (control group minus MBPT group) increases over time; the increase is highly significant. The correlation coefficient between the median differences and the survey points in time was calculated (Spearman- $\rho)$ : $\rho=0.63$, $(p<0.01)$. (Fig.1)

\section{EuroQol 5-D}


In the EQ-5D-evaluation, the MBPT-group reported a significant improvement. The patients of the experimental group declared an increase in quality of life from $50 \%$ (pre) to $85 \%$ (post) and after three months it settled at 75\%, against a marginal increase in the control group (Pre: $45 \%$ Follow-up at 3 months: $50 \%$ ) (Table 1). The value in the follow-up at 1 month is statistically significant ( $p=0.036 ; \mathrm{U}$ test) as well as the time progression of median differences ( $p=0.015$; one sample t-test). However, when comparing the single subscales of the two group, differences were not significant. (Fig. 2)

\section{Pain perception Scale PPS}

The MBPT-group has consistently lower values than the control group, in some cases significant (post) ( $p$ $=0.01$ or $\mathrm{p}=0.03$; exact U-test). (Table 2 and 3 ) (Fig. 3 and 4 )

\section{Pain disability index}

Significant changes in pain-related disability were observed in the MBPT-Group immediately at post and at 1 month ( $p=0.03$ and 0.04, exact U-test). (Table 4) (Fig. 5)

\section{Beck Depression Inventory}

Although the differences at the single measurement points are not significant, the progressive increase of the median differences between the two groups is remarkable. (Table 5) (Fig. 6)

\section{Pain Catastrophizing Scale}

The MBPT group demonstrates a significant decrease in pain catastrophizing value from baseline compared with control group. Results indicate that pain catastrophizing reduction was maintained over 1month to 3-month follow-up periods. (Table 6) (Fig. 7)

\section{Discussion}

Although several studies have examined the effects of mindfulness on chronic pain, $[\mathrm{i}]^{[i i]}$ to our knowledge, this is the first study to evaluate the feasibility of an intensive mindfulness-based meditation program within the multimodal pain therapy. We hypothesized that mindfulness intervention in the multimodal pain therapy would ameliorate the results of the standard multimodal pain treatment. Results supported the hypotheses.

We found that MBPT Program within multimodal pain management was associated with better pain management compared to the control group. It also provided evidence of increases in well-being and quality of life as well as decreases in pain intensity, disability, depression and catastrophizing. The completion rate was very high in both groups.

A decrease in pain intensity in the intervention group was highly significant, as well as the reported quality of life increased. Further, significant effects were observed in reduction of the disability. 
The findings suggest that MBPT is more effective than multimodal standard therapy alone in significantly improving quality of life, reducing disability, depression and catastrophizing related to chronic pain. These effects were partly maintained at 3-month follow-up.

Patients with chronic pain may profit from mindfulness meditation through various mechanisms.

In line with Hölzel et al. we assume that the positive effects of mindfulness on chronic pain can be attributed to different mechanisms.[iii]

Attention regulation, body awareness, emotion regulation through acceptance and change in perspective on the self.

\section{1)Attention regulation}

Attention regulation is central to many mindfulness-based interventions. Attention can be metaphorically described as a constantly moving spotlight which illuminates certain aspects of the experience, leaving others in the darkness. Patients with chronic pain frequently have their attention selectively focused on their pain (attentional bias) [iv] investing a considerable amount of time ruminating on their pain, its causes and consequences. Mindfulness meditation aims to counterbalance these tendencies by stabilizing attentional skills. It has been postulated that mindfulness reduces depressive symptoms by lowering the process of thinking perseveratively about one's feelings and problems.[v]

2) Body awareness

Some authors reported altered body awareness in chronic pain patients[vi] and a positive correlation between body awareness and mindfulness.[vii] Mindfulness may contribute in disengaging from selective pain-related perceptions, offering a broader perspective to the person allowing a wider range of experience, as opposed to a narrowed focus on the perceptual field of the pain. Some patients reported, for example: "I realized that besides the pain in my back I have other sensations, some of them even pleasant".

3) emotion regulation through acceptance

There is a considerable amount of evidence that the process of trying to control the experience of chronic pain (avoidance) can lead to an exacerbation of the perception of pain.[viii] At the same time maladaptive emotion regulation can be an important risk factor in the development and maintenance of chronic pain. [ix]

At the opposite pole, acceptance seems to be a factor that significantly influences patients' emotion regulation and thus quality of life. Acceptance is associated with lower pain intensity, less pain-related anxiety, less physical and psychological disability. [x] More over pain catastrophizing has been found to be an inverse correlate of acceptance.[xi] Letting go of struggle and acceptance of one's condition without judgment is a critical concept in the mindfulness-based interventions. 
We define acceptance as an allowing and open-minded stance toward all experience particularly those which are unwanted and unchangeable. Acceptance allows an understanding of reality as it is and helps to avoid the extremes of unproductive resistance and passive resignation and enables a realistic assessment of one's own possibilities in the present moment. Acceptance is the attitude of understanding that things are not always as one would like them to be. It is neither approval nor resignation to the reality of things as they actually are.

Some participants reported, for instance, that accepting their situation allowed them to discover new coping strategies of responding to pain (empowerment). Others stated for example: "I learned new ways to deal with my pain."

4) Change in perspective on the self

Chronic pain interferes commonly with essential life goals of the patients and may have profound impact on patient's sense of self. Patients frequently reported feeling useless, unable to pursue their personal plans. Statements such as: "my life is a catastrophe" or "am not able to manage my pain" were very common among the groups.

During the program we could see, consistent with the findings of other authors[xii] a remarkable change in perspective. Some patients stated for example: "I am not my pain" or "my pain does not define me" or "I learned to deal with my pain" showing a radical change in the way the patient relates to his own condition. Some authors have termed this process "reperceiving" or "decentering."[xiii]

We believe the positive impact on the assessed measures was partly due to the sum of time of practice, which could be with better results. In our study participants of the MBPT-Group had an intensive daily practice $(2 h)$.

Despite overall promising results, it is noticeable that there was no significant difference between MBPTGroup and control group in some fundamental measures such as mindfulness levels, measured with Five Facet Mindfulness Questionnaire (FFMQ). This could have several reasons. We speculate that both groups may have gained through the physical activity a certain degree of mindfulness.[xiv] Furthermore, the study did not observe significant differences in sleep quality when MBPT was compared to the control group, although other studies have found a positive correlation between mindfulness and sleep quality.[xv]

\section{Limitations}

Results of the current study should be interpreted in light of several limitations. The study was not strictly randomized and had a small sample size. A stratification by age should have been applied in order to ensure equal allocation of participants. 


\section{Conclusions}

In summary the MBPT-Program represents a meaningful and feasible non-pharmacologic addition to the current multimodal treatment for chronic pain.

We suggest that utilizing mindfulness meditation (e.g. MBPT) adjunctively with standard multidisciplinary treatment can lead to greater efficacy of the treatment and as a result appears promising and a viable alternative for the treatment of chronic low back pain.

More research is needed on larger samples, which may achieve more significant results. Future studies may examine the mechanisms by which mindfulness interventions reduce pain.

\section{Abbreviations}

MBI Mindfulness-Based Interventions

MBPT Mindfulness-Based Pain Therapy

MBSR Mindfulness-Based Stress Reduction

CLBP Chronic Low Back Pain

\section{Declarations}

\section{Funding}

No funding or sponsorship was received for this study or publication in this article

\section{Authorship}

All named authors meet the international Committee of Medical Journal Editors (ICMJE) criteria for authorship for this article, take responsibility for the integrity of the work as a whole, and have given their approval for this version to be published

The authors thank Dr. Haro Stettner for statistical support.

\section{Conflict of interest statement}

None of the authors have conflicts of interest to declare

\section{References}

1. Classification of chronic pain. Descriptions of chronic pain syndromes and definitions of pain terms. Prepared by the International Association for the Study of Pain, Subcommittee on Taxonomy. Pain Suppl. 1986; 3: S1-226. 
2. International Association for the Study of Pain: "The Relief of Pain Should Be a Human Right" https://www.iasp-pain.org/GlobalYear/RighttoPainRelief

3. Phillips CJ. The Cost and Burden of Chronic Pain. Rev Pain. 2009; 3(1): 2-5.

4. Breivik H, Collett B, Ventafridda V, Cohen R, Gallacher D. Survey of chronic pain in Europe: prevalence, impact on daily life, and treatment. European Journal of Pain. 2006; 10: 287-333.

5. Breivik H, Eisenberg E, O'Brien T. The individual and societal burden of chronic pain in Europe: the case for strategic prioritisation and action to improve knowledge and availability of appropriate care. BMC Public Health. 2013; 13: 1229.

6. Geneen LJ, Moore RA, Clarke C, Martin D, Colvin LA, Smith BH. Physical activity and exercise for chronic pain in adults: an overview of Cochrane Reviews. Cochrane Database Syst Rev. 2017; 1(1):CD011279.

7. Savage SD. Long-term opioid therapy: Assessment of consequences and risks, Journal of Pain and Symptom Management. 1996; 11 (5)1996; 274-286,

8. Mills S, Torrance N, Smith BH. Identification and Management of Chronic Pain in Primary Care: a Review. Curr Psychiatry Rep. 2016; 18: 22

9. Dysvik E, Kvaløy JT, Stokkeland R, Natvig GK. The effectiveness of a multidisciplinary pain management programme managing chronic pain on pain perceptions, health-related quality of life and stages of change - a nonrandomized controlled study. Int J Nurs Stud 2010; 47: 826-835

10. Dale R, Stacey B. Multimodal treatment of chronic pain. Med Clin North Am. 2016; 100(1): 55-64.

11. Arnold B, Brinkschmidt T, Casser HR, et al. Multimodal pain therapy for treatment of chronic pain syndrome. Consensus paper of the ad hoc commission on multimodal interdisciplinary pain management of the German Pain Society on treatment contents. Schmerz 2014; 28(5): 459-472.

12. Arnold B, Brinkschmidt T, Casser, HR. et al. Multimodale Schmerztherapie. Schmerz 2009; 23: 112 (2009).

13. Kabat-Zinn J. Full catastrophe living: how to cope with stress, pain and illness using mindfulness meditation. London: Piatkus, 1996.

14. Kabat-Zinn J. Mindfulness-based interventions in context: past, present, and future. Am Psychol Assoc. 2003; 10 (N2): 144-156.

15. Kabat Zinn J and Ludwig David S, Mindfulness in Medicine JAMA. 2008; 300, No. 11

16. Brown KW, Ryan RM. The benefits of being present: Mindfulness and its role in psychological wellbeing. Journal of Personality and Social Psychology 2003; 84(4): 822-848.

17. Krygier JR, Heathers JAJ, Shahrestani S, Abbott M, Gross JJ, Kemp AH. Mindfulness meditation, wellbeing, and heart rate variability: A preliminary investigation into the impact of intensive Vipassana meditation. Int Journal of Psychophysiology 2013; 89 (3): 305-313

18. Kabat-Zinn J. An outpatient program in behavioral medicine for chronic pain patients based on the practice of mindfulness meditation: theoretical considerations and preliminary results. Gen Hosp Psychiatry. 1982; 4(1):33-47. 
19. Baer RA. Mindfulness training as a clinical intervention: A conceptual and empirical review. Clinical Psychology: Science and Practice 2003; 10(2): 125-143.

20. Hilton L, Hempel S, Ewing BA, et al. Mindfulness Meditation for Chronic Pain: Systematic Review and Meta-analysis, Annals of Behavioral Medicine 201751 (2): 199-213.

21. Goyal M, Singh S, Sibinga EMS, et al. Meditation Programs for Psychological Stress and Well-being: A Systematic Review and Meta-analysis. JAMA Intern Med. 2014; 174(3): 357-368.

22. Santorelli SF, Meleo-Meyer F, Koerbel L. Mindfulness-Based Stress Reduction (MBSR) Authorized Curriculum Guide 2017. University of Massachusetts Medical School

23. Kabat-Zinn J, Chapman-Waldrop A. Compliance with an outpatient stress reduction program: rates and predictors of program completion. J Behav Med 1988; 11: 333-352.

24. Childs JD, Piva SR, Fritz JM. Responsiveness of the numeric pain rating scale in patients with low back pain. Spine (Phila Pa 1976). 2005; 30(11): 1331-1334.

25. Michener LA, Snyder AR, Leggin BG. Responsiveness of the numeric pain rating scale in patients with shoulder pain and the effect of surgical status. J Sport Rehabil. 2011; 20(1): 115-128.

26. EuroQol Group. EuroQol: a new facility for the measurement of health-related quality of life. Health Policy 1990; 3: 199-208.

27. Soer R, Reneman MF, Speijer BL, Coppes MH, Vroomen, PC (2012). Clinimetric properties of the EuroQol-5D in patients with chronic low back pain. The Spine Journal: official Journal of the North American Spine Society. 2012; 12(11): 1035-1039

28. Geissner E. Die Schmerzempfindungsskala (SES) Handanweisung, Göttinger, Hogrefe, 1996

29. Geissner E. [The Pain Perception Scale--a differentiated and change-sensitive scale for assessing chronic and acute pain] Die Rehabilitation. 1995; 34(4): 35-43.

30. Chibnall JT, Tait RC. The Pain Disability Index: Factor structure and normative data. Archives of Physical Medicine and Rehabilitation. 1994; 75: 1082-1086.

31. Dillmann U, Nilges P, Saile H, Gerbershagen HU. Behinderungseinschätzung bei chronischen Schmerzpatienten. Schmerz 8, 1994; 100-110

32. Beck AT, Steer RA, Brown G. Beck Depression Inventory-II. APA PsycTests. 1996

33. Gallagher D, Nies G, Thompson LW. Reliability of the Beck Depression Inventory with older adults. Journal of Consulting and Clinical Psychology, 1982; 50(1): 152-153.

34. Kühner C, Bürger C, Keller F, Hautzinger M. [Reliability and validity of the Revised Beck Depression Inventory (BDI-II). Results from German samples]. Der Nervenarzt. 2007; 78(6): 651-656.

35. Sullivan M JL, Bishop S, Pivik J. The Pain Catastrophizing Scale: Development and validation. Psychol Assess 1995; 7: 524-532.

36. Meyer K, Sprott H, Mannion, AF. Cross-cultural adaptation, reliability, and validity of the German version of the Pain Catastrophizing Scale. Journal of Psychosomatic Research 2008; 64(5): 469478. 
37. Kabat-Zinn J. An outpatient program in behavioral medicine for chronic pain patients based on the practice of mindfulness meditation: Theoretical considerations and preliminary results. ReVISION 1984; 7(1): 71-72

38. Kabat-Zinn J, Lipworth L, Burney R. The clinical use of mindfulness meditation for the self-regulation of chronic pain. J Behav Med 1985; 8, 163-190

39. Hölzel BK, Lazar SW, Gard T, Schuman-Olivier Z, Vago DR, Ott U.. Perspectives How Does Mindfulness Meditation Work? Proposing Mechanisms of Action From a Conceptual and Neural Perspective on Psychological Science.2015; 6(6) 537-559

40. Dehghani M, Sharpe L, Nicholas MK.. Modification of attentional biases in chronic pain patients: a preliminary study. Eur Journal of Pain 2004; 6; 585-94

41. Teasdale JD, Moore RG, Hayhurst H, Pope M, Williams S, Segal ZV. Metacognitive awareness and prevention of relapse in depression: Empirical evidence. Journal of Consulting and Clinical Psychology. 2002; 70(2), 275-287.

42. Gard G. Body awareness therapy for patients with fibromyalgia and chronic pain. Disability and Rehabilitation. 2005; 27(12):725-728

43. Ribera d'Alcalà C, Webster DG, Esteves JE, Interoception, body awareness and chronic pain: results from a case-control study, International Journal of Osteopathic Medicine. 2014

44. Cioffi D, Holloway, J. Delayed Costs of Suppressed Pain. Journal of Personality and Social Psychology 1993 64(2):274-82

45. Koechlin H, Coakley R, Schechter N, Werner C, Kossowsky J. The role of emotion regulation in chronic pain: A systematic literature review, Journal of Psychosomatic Research, 2018; 107, 38-45

46. McCracken LM, Eccleston E. A prospective study of acceptance of pain and patient functioning with chronic pain Pain.2005; 118, 164-169

47. Ruskin D, Harris L, Stinson J, Mccarthy E, Kohut SA, Walker K. „I learned to let go my pain” The effects of mindfulness meditation on adolescents with chronic pain: An Analysis of Participant's treatment experience. Children 2017; 4, 110

48. Atkins P. Styles R. Mindfulness, identity and work: Mindfulness training creates a more flexible sense of self. Mindfulness in Organizations: Foundations, Research, and Applications. Cambridge University Press. 2015; 133-162

49. Olendzki A. The transformative impact of non-self. Buddhist thought and applied psychological research: Transcending the boundaries. 2006; 250-261

50. Xia T, Hu H, Seritan AL, Eisendrath S. The Many Roads to Mindfulness: A Review of NonmindfulnessBased Interventions that Increase Mindfulness. The Journal of Alternative and Complementary Medicine 2019; 25 (9)

51. Howell AJ. Digdon NL. Buro K. Sheptycki AR. (2008) Relations among mindfulness, well-being, and sleep, Personality and Individual Differences 2008; 45 (8): 773-777. 


\begin{tabular}{|lllllllll|}
\hline & \multicolumn{3}{c}{ Control Group } & \multicolumn{7}{c|}{ MBPT Group } \\
\hline EQ 5D Evaluation & $\mathrm{N}$ & Median & Mean & SDEV & $\mathrm{n}$ & Median & Mean & SDEV \\
\hline $\mathrm{p}$ & 10 & 45 & 51.8 & 19.1 & 10 & 50 & 47.3 & 12.4 \\
\hline Post & 9 & 69 & 66.1 & 17.8 & 9 & 85 & 74 & 24 \\
\hline 1-Month & 7 & 60 & 58.7 & 15.3 & 8 & 80 & 75.3 & 18.3 \\
\hline 3-Month & 7 & 50 & 56.6 & 20.9 & 7 & 75 & 71.4 & 20.1 \\
\hline
\end{tabular}

Tab.1. EuroQol 5-D

\begin{tabular}{|lllllllll|}
\hline \multicolumn{3}{c}{ Control Group } & \multicolumn{5}{c|}{ MBPT Group } \\
\hline Affective & $\mathrm{n}$ & Median & Mean & SDEV & $\mathrm{N}$ & Median & Mean & SDEV \\
$\mathrm{p}$ & 10 & 29.5 & 32 & 11 & 9 & 34 & 35 & 11.2 \\
\hline Post & 9 & 27 & 26 & 7.2 & 9 & 18 & 19.4 & 4.3 \\
\hline 1-Month & 6 & 24 & 23 & 3.8 & 8 & 16.5 & 19.8 & 7.6 \\
\hline 3-Month & 7 & 25 & 25.6 & 8.4 & 7 & 17 & 19.6 & 5.2 \\
\hline
\end{tabular}

Tab. 2. Pain Perception Scale - Affective

\begin{tabular}{|lllllllll|}
\hline \multicolumn{3}{|c}{ Control Group } & \multicolumn{7}{c|}{ MBPT Group } \\
\hline Sensory & $\mathrm{n}$ & Median & Mean & SDEV & $\mathrm{N}$ & Median & Mean & SDEV \\
$\mathrm{p}$ & 10 & 25 & 24 & 6.8 & 10 & 20 & 23.8 & 7.6 \\
\hline Post & 9 & 21 & 20 & 5.1 & 9 & 13 & 14.8 & 4.1 \\
\hline 1 month & 7 & 20 & 19.6 & 6.9 & 8 & 15.5 & 16.8 & 6.1 \\
\hline 3 month & 7 & 19 & 20.1 & 6.9 & 7 & 18 & 17.4 & 5.4 \\
\hline
\end{tabular}

Tab. 3. Pain Perception Scale - Sensory 


\begin{tabular}{|lllllllll|}
\hline \multicolumn{4}{|c}{ Control Group } & \multicolumn{7}{c|}{ MBPT Group } \\
\hline PDI & $\mathrm{n}$ & Median & Mean & SDEV & $\mathrm{n}$ & Median & Mean & SDEV \\
\hline $\mathrm{p}$ & 10 & 31.5 & 29.1 & 8.2 & 10 & 33 & 32.3 & 12.3 \\
\hline Post & 9 & 23 & 22.2 & 9.6 & 9 & 13 & 13.2 & 7.4 \\
\hline 1-Month & 7 & 18 & 23.1 & 11.8 & 7 & 9 & 13 & 10.6 \\
\hline 3-Month & 7 & 18 & 15.4 & 10.1 & 7 & 12 & 14.7 & 12.1 \\
\hline
\end{tabular}

Tab. 4. Pain Disability Index

\begin{tabular}{|lllllllll|}
\hline & \multicolumn{3}{c}{ Control Group } & \multicolumn{5}{c|}{ MBPT Group } \\
Spaltentitel & $\mathrm{N}$ & Median & Mean & SDEV & $\mathrm{n}$ & Median & Mean & SDEV \\
$\mathrm{p}$ & 10 & 19.5 & 18.7 & 9.9 & 10 & 16.5 & 15.8 & 6.2 \\
\hline Post & 9 & 10 & 11.6 & 11.4 & 8 & 8 & 7.6 & 6.3 \\
1-Month & 7 & 10 & 7.9 & 5 & 8 & 7.5 & 8.8 & 8.4 \\
\hline 3-Month & 7 & 12 & 11.6 & 7.6 & 7 & 6 & 9.1 & 9.2 \\
\hline
\end{tabular}

Tab. 5. Beck Depssion Inventory

\begin{tabular}{|lllllllll|}
\hline \multicolumn{4}{|c}{ Control Group } & \multicolumn{5}{c|}{ MBPT Group } \\
\hline PCS & $\mathrm{n}$ & Median & Mean & SDEV & $\mathrm{n}$ & Median & Mean & SDEV \\
\hline $\mathrm{p}$ & 10 & 26 & 24.2 & 11.1 & 10 & 23.5 & 24.9 & 11 \\
\hline Post & 9 & 18 & 15.6 & 9.4 & 9 & 6 & 7.7 & 8.2 \\
\hline 1-Month & 7 & 11 & 12.6 & 6.5 & 9 & 3 & 7.9 & 7.8 \\
\hline 3-Month & 7 & 16 & 14.9 & 10.5 & 7 & 10 & 10.9 & 9.2 \\
\hline
\end{tabular}

Tab. 6. Pain Catastrophizing Scale

Figures 


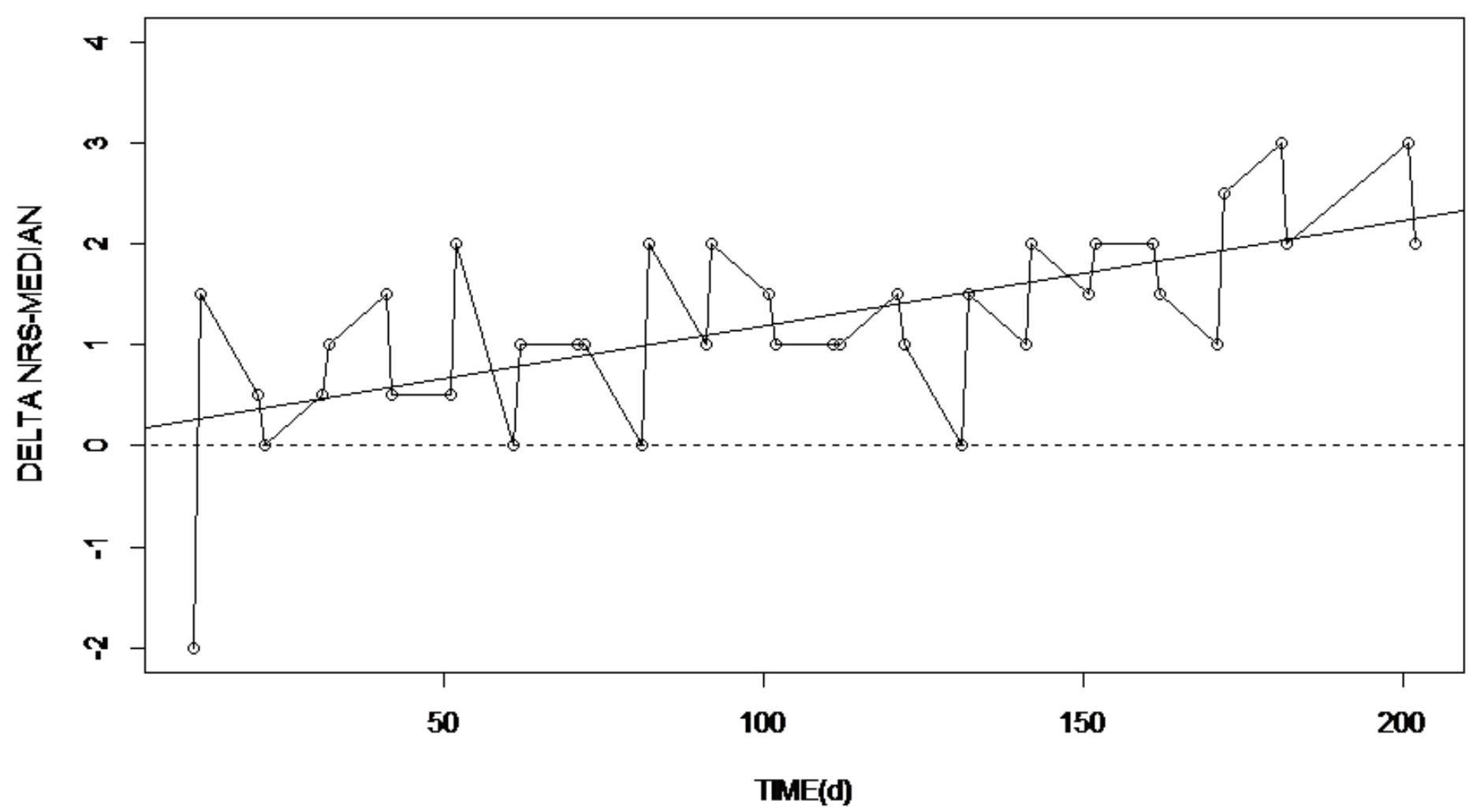

\section{Figure 1}

Time progression of the NRS median differences. MBPT patients have highly significant lower pain scores $(p<0.01$; signed rank test). 


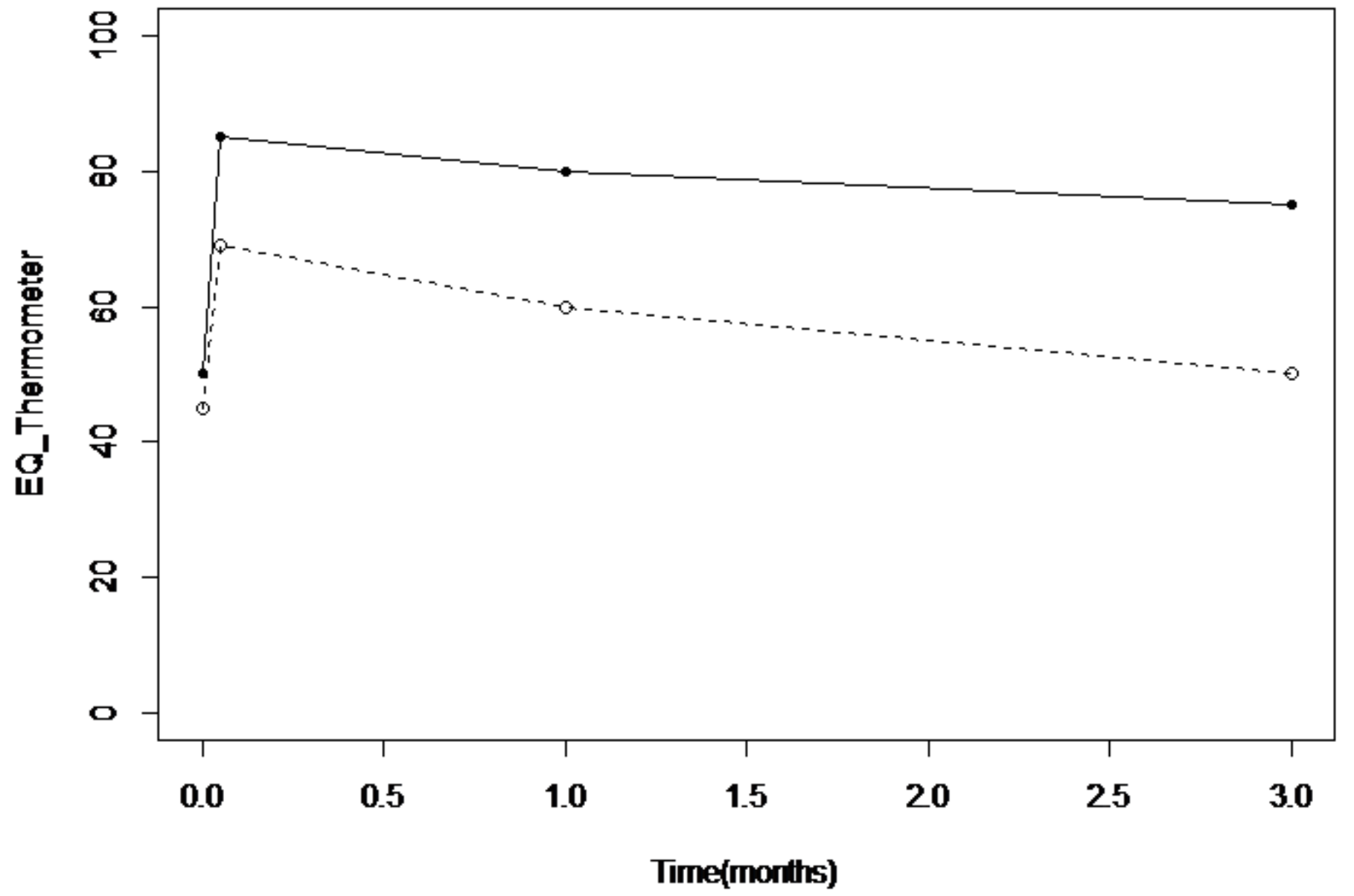

Figure 2

Trend of the EQ Thermometer medians for MBPT group $(\cdot)$ and control group: $(\circ)$. The values at POST differ weakly significantly $(p=0.095 ; U$ test $)$, the values of the follow up at one month differ significantly $(p=0.036 ; U$ test $)$. 


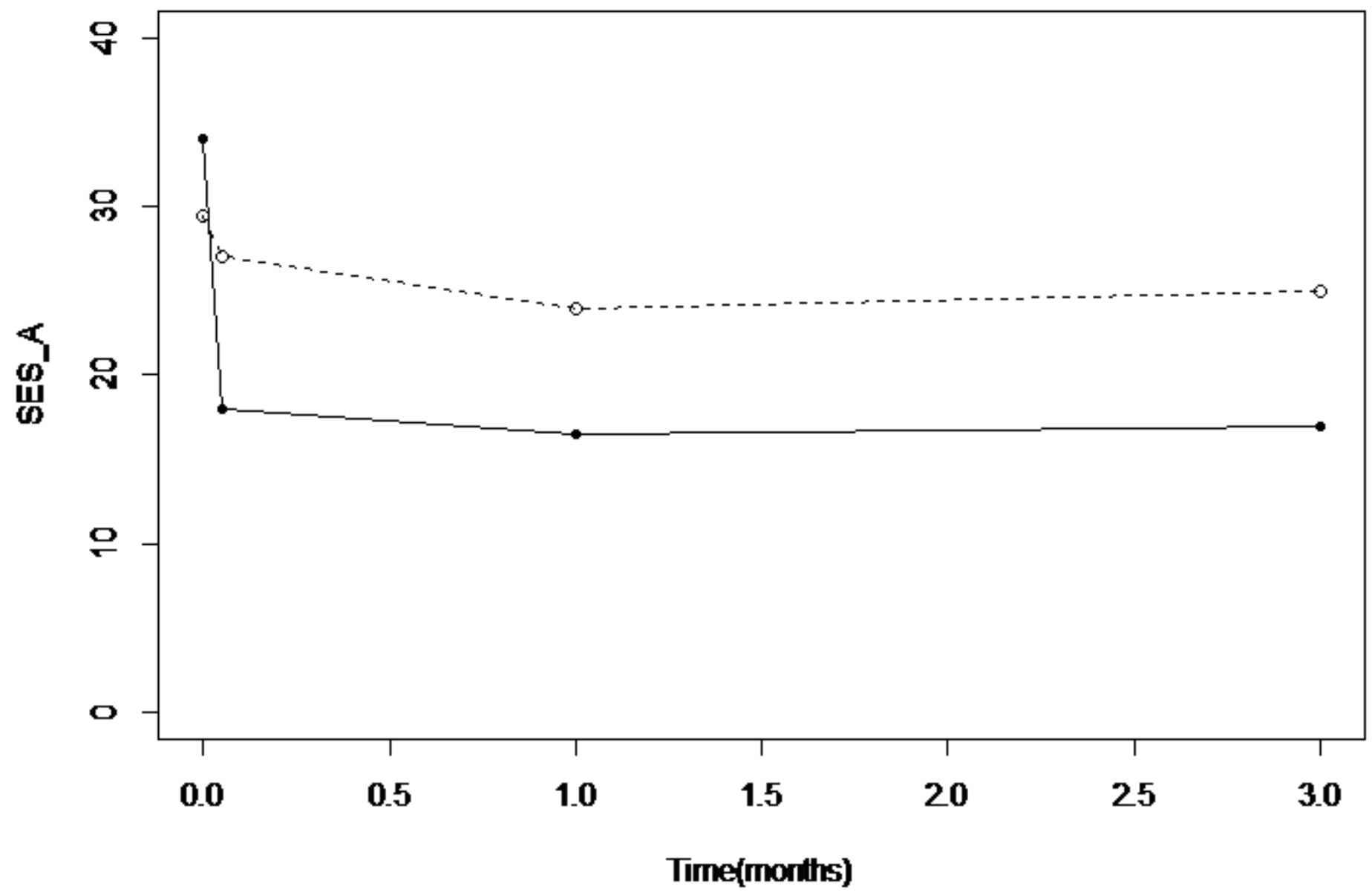

Figure 3

Trend of SES_A medians for MBPT group $(\cdot)$ and control group ( () . The groups differ significantly at POST ( $p=0.012$, U test). 


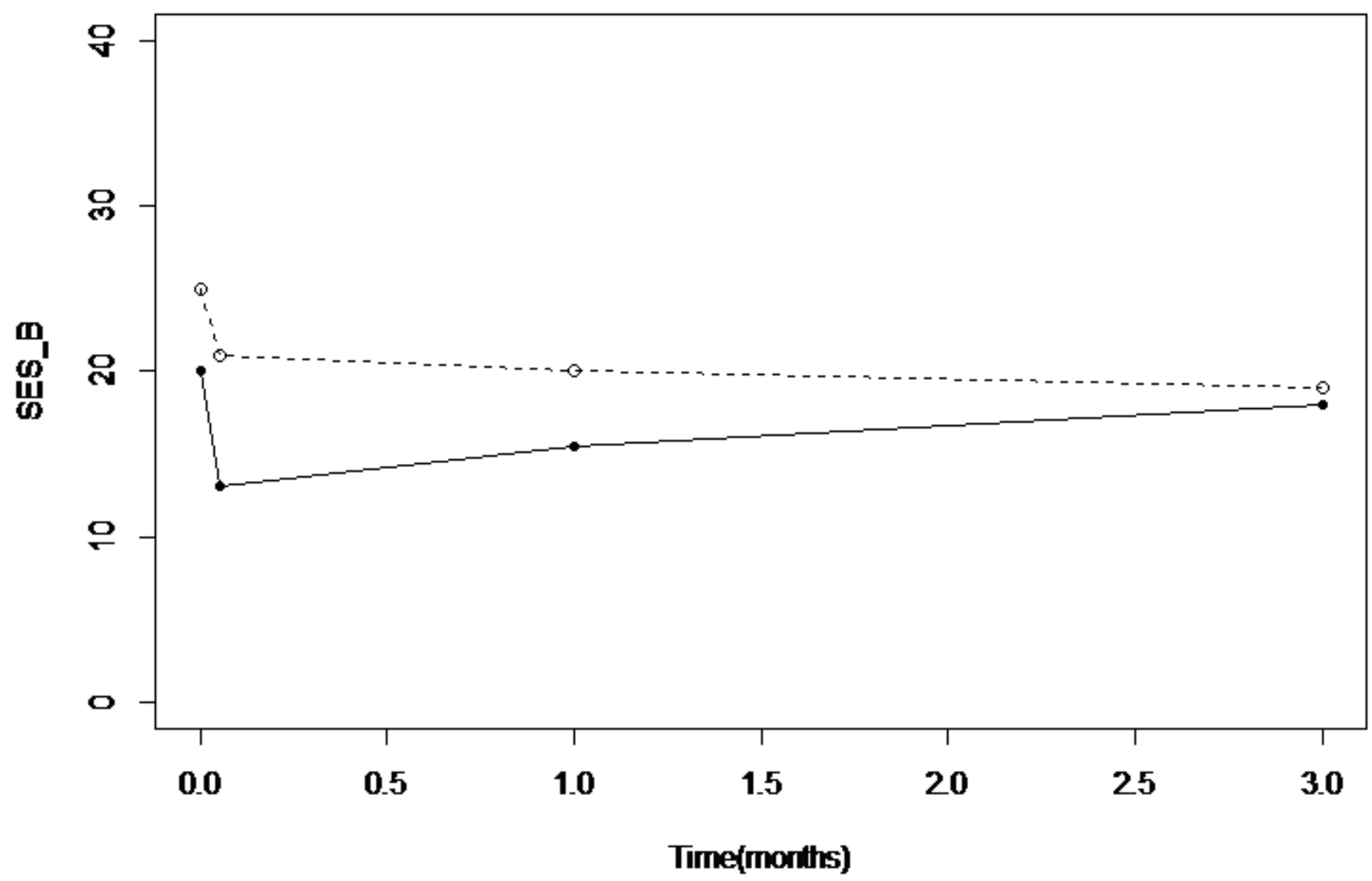

Figure 4

Trend of the SES_B medians for MBPT group ( $\cdot$ ) and control group (०). The groups differ significantly at POST $(p=0.025$, U test). 


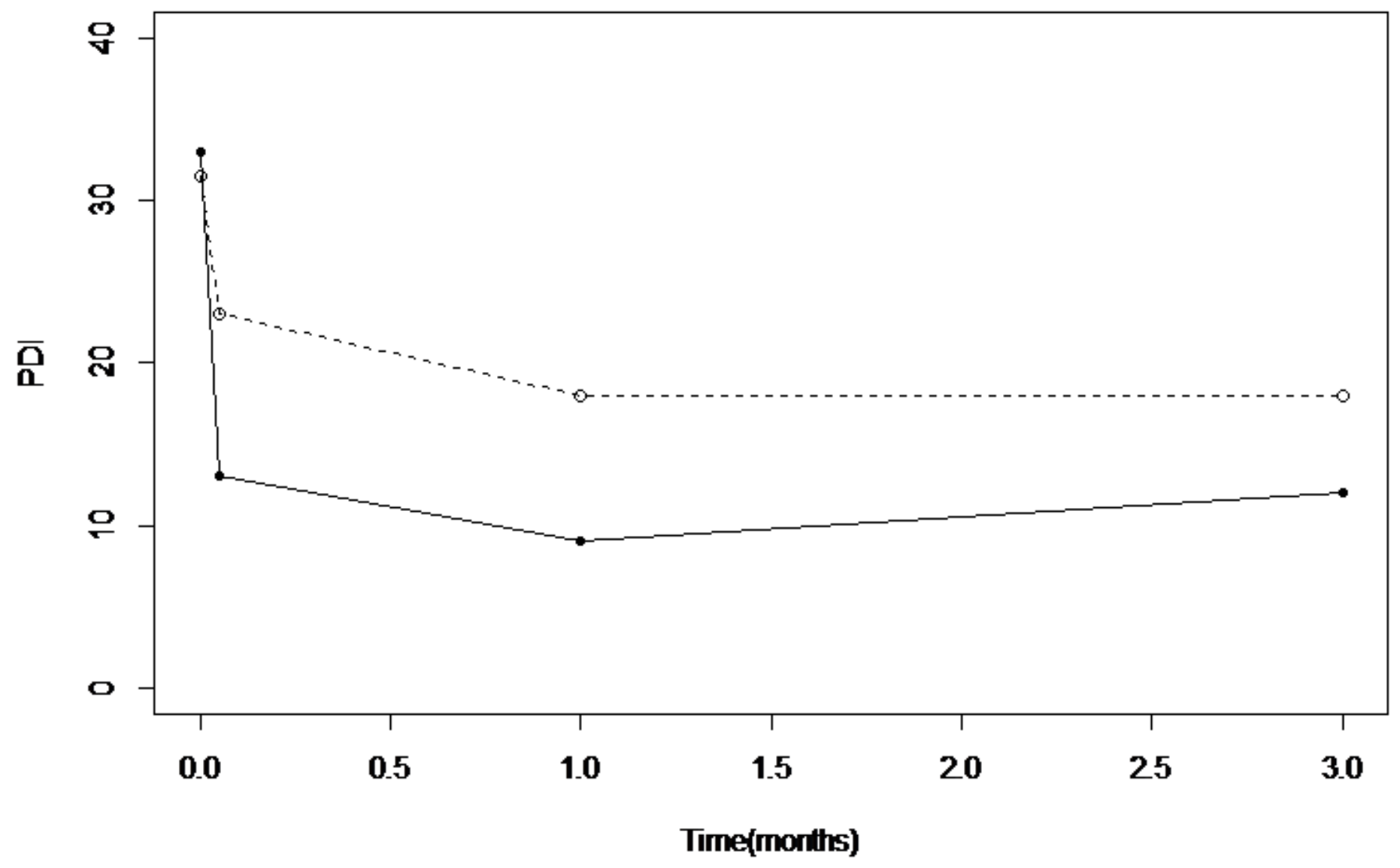

Figure 5

Trend of PDI medians for MBPT group ( $\cdot$ ) and control group (o). The groups differ significantly at one month $(p=0.025, U$ test $)$. And three months $(p=0.036$, $U$ test $)$ 


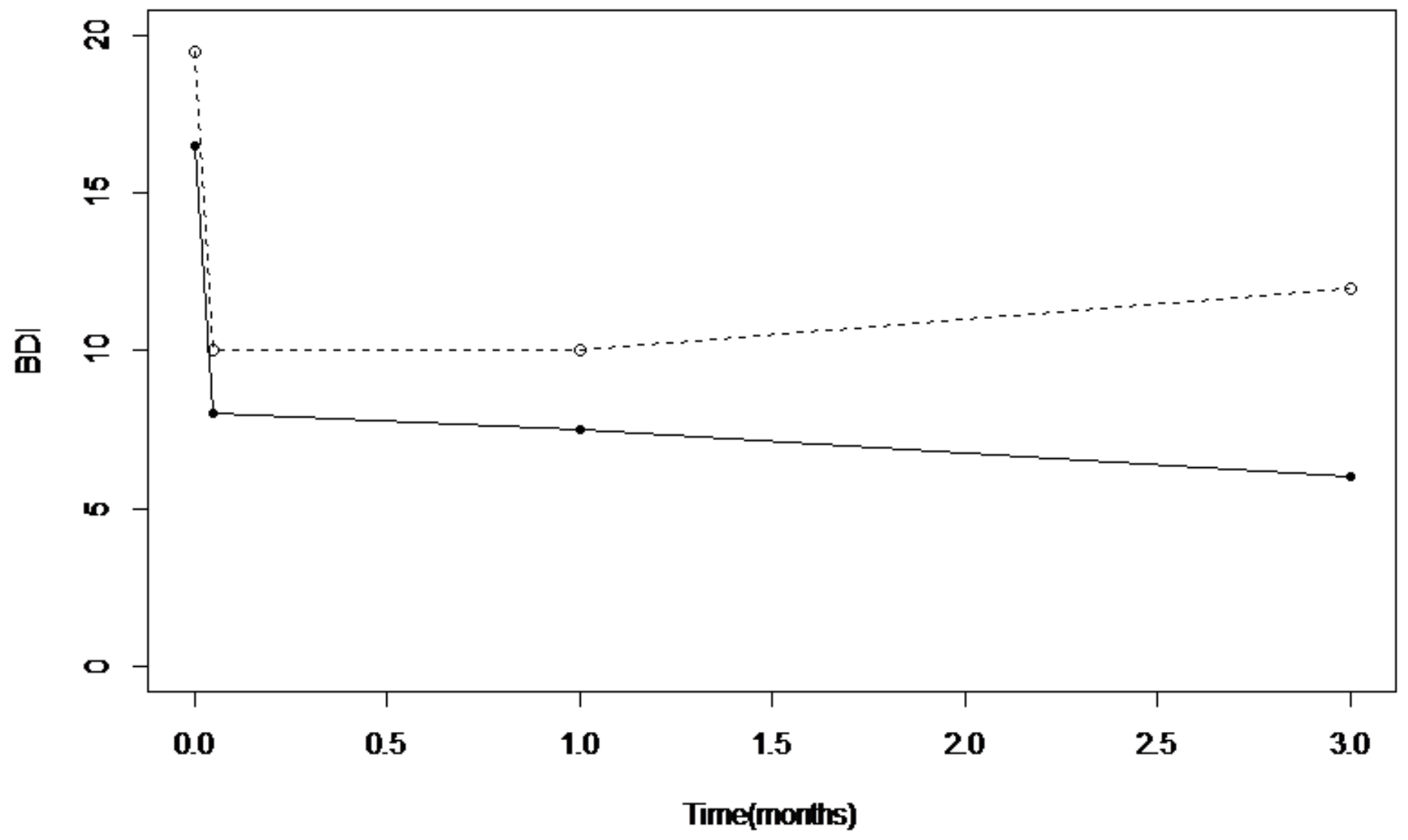

Figure 6

Trend of BDI medians for MBPT group $(\cdot)$ and control group $(\circ)$. Differences between the groups are not significant. 


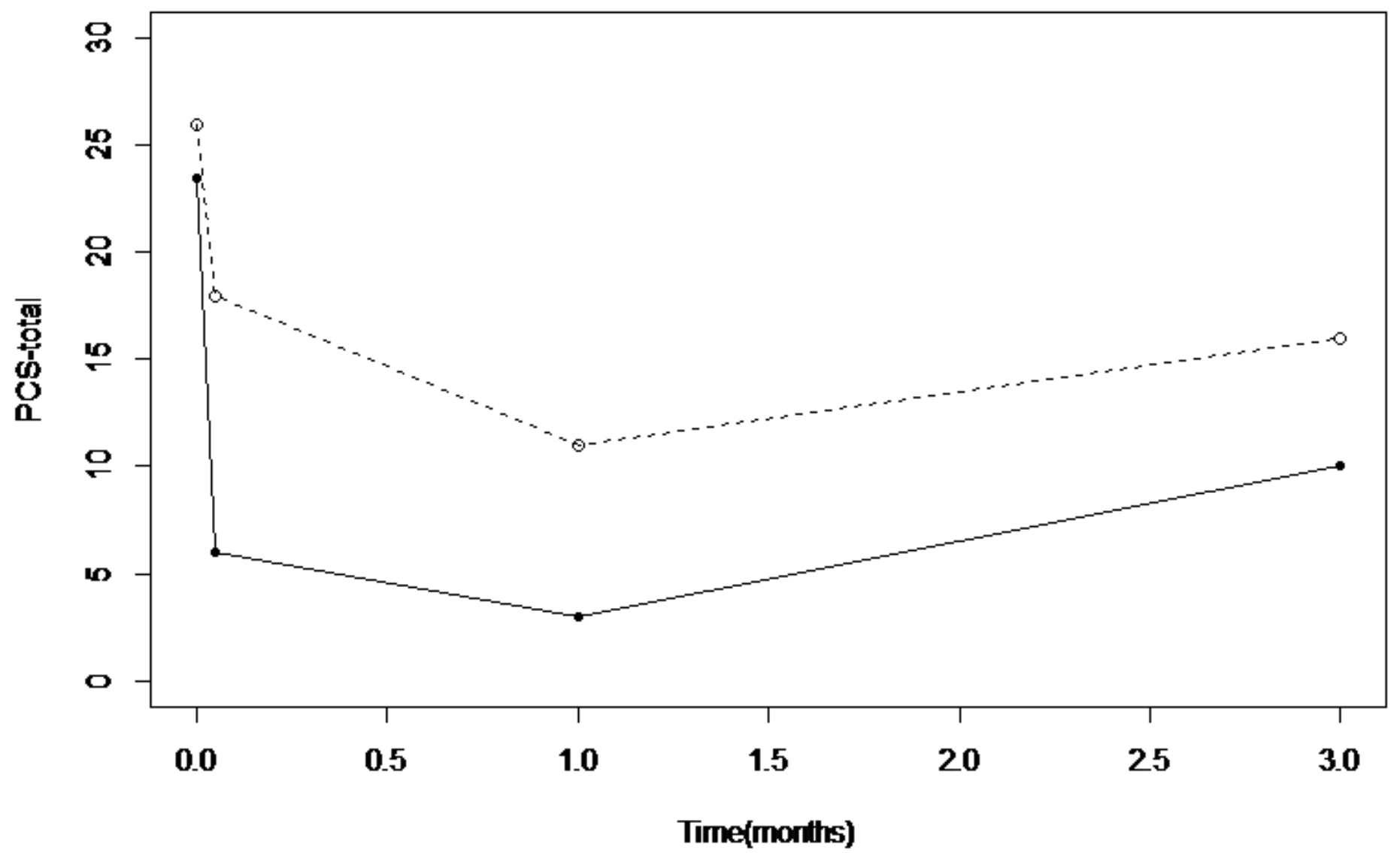

Figure 7

Time progression of the PCS medians of the two therapy groups (therapy group: - ; control group: $)$ ). The two groups differ significantly in PCS-total post ( $p=0.047$; exact U-test). 